\title{
A Student's Axiomatic Design Application Example of Battery Thermal Controller for High Altitude Balloon
}

\author{
Yuchen Wang ${ }^{1, *}$, Ang Liu ${ }^{1}$ \\ ${ }^{1}$ University of New South Wales, School of Mechanical and Manufacturing Engineering, NSW Kensington 2052, Australia
}

\begin{abstract}
The axiomatic design plays a critical role in transferring FRs into DPs and organising scattered design information. Nowadays, the axiomatic design is commonly applied to student engineering design education. Although it assists design organisation, some procedures can be challenging for invoice students. This paper is written to reflect benefits, challenges and potential mistakes when the axiomatic design is applied by invoice students. The reflection is based on a case study, a student lead battery thermal controller (BTC) on a high-altitude balloon is used as the example. Relevant background about the high-altitude balloon was introduced at first. Previous essential information of customer domain and functional domain was clarified before the axiomatic design. Design parameters(DPs) were generated with Morphological Chart to compose candidate concepts. FR-DP matrix was used to evaluate the independence of functional requirements(FRs). Candidate concepts were then selected by probability density function graphs. The most proper concept then was out of Pugh's Matrix. Through this axiomatic design application, benefits, challenges and potential mistakes were reflected for invoice students. Benefits included convenient errors correction and competent concepts generation. Challenges contain the DPs performance value determination and physical integration of concept. Potential mistakes include generation of inconsistent performance value for bottomlevel FRs and invalid DPs.
\end{abstract}

\section{Introduction}

As the bridge between functional domain and concept domain, the axiomatic design is commonly used to generate well-organised engineering design concepts and assist decision making. To date, the axiomatic design has been applied in engineering design education in a wide range. Compared to experienced engineers in academic and industrial work, invoice students are relatively lack of mature technical skills, problem-solving experience, and professional engineering habits. Although the axiomatic design has a general sequence, some procedures are still highly flexible, such as candidate DPs generation and concept evaluation preference. To satisfy customer demands, experience, technical skills and resources are essential to assist decision making when dealing with these flexible procedures. As a result, invoice students might find it challenging to apply several procedures properly. Considering this feature, for students' engineering design education of the axiomatic design, educators should think of possible challenges for invoice students. In correspondence to these challenges, special educational strategies should be applied to help students apply the axiomatic design properly.

This paper is written to explore benefits, challenges and potential mistakes of the axiomatic design when applied by primary students. These features are discussed based on a case study, a student lead BTC development project is used as the example. Section 2 will introduce relevant customer review and functional domain results at first. In section 4, independent axiom design is presented at first, including concepts generation and independence check. For information axiom design, DPs are compared via probability density graphs, and concepts are compared by Pugh's matrix. In addition, all concepts are visualised, and the chosen concept is displayed by CAD model. In each procedure, the student's reflection of benefits, challenges and mistakes are clarified, which will be summarised in final discussion. This paper majorly focuses on the axiomatic design application itself. The BTC is used as a case study only, and technical details are not specifically clarified. The applied axiomatic design procedures in this case study is presented in Figure 1.

This case study is representative for research purpose of the paper. For the BTC development project, the motivation of this student lead project is to improve students' design, research, manufacturing and test skills. The required objective does not require knowledge beyond the student's ability. Hence, central of this project is on design rather than technical problems. Meanwhile, the BTC involves coordination of various system, which can be a good platform to test design issues such as FRs management, constraints management and DPs independence. For the student, the developer of this BTC is an undergraduate aerospace engineering student, who finished the axiomatic design study in the previous semester, and this project is his first isolation of the design

* Yuchen Wang: yuchenwang2@,student.unsw.edu.au 
theory application. Therefore, the student can be a typical example of invoice engineering student.

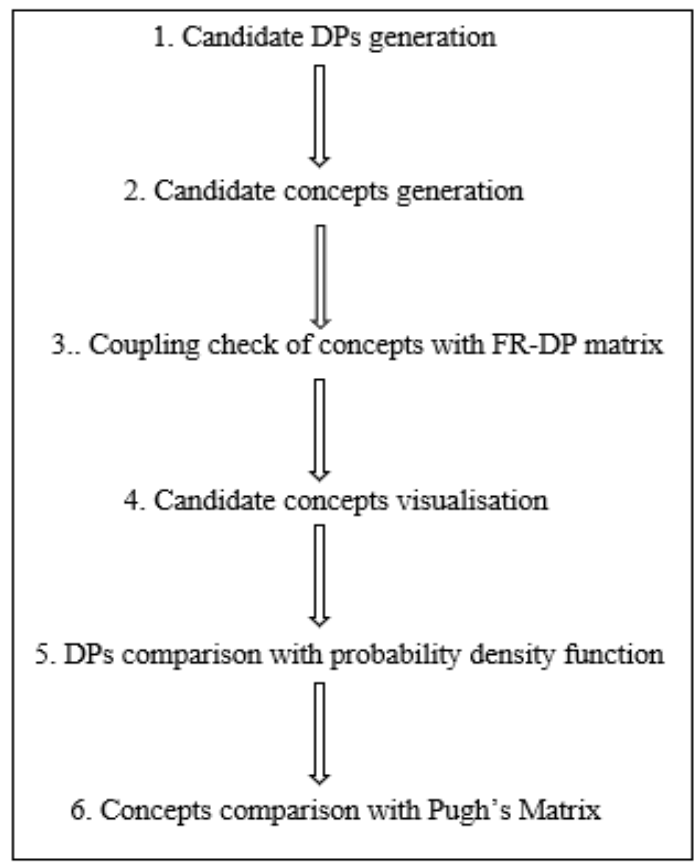

Fig. 1. Flow Chart of Axiomatic Design Procedures

\section{Background of High Altitude Balloon}

The high-altitude balloon refers to an objectiveassigned carrier, which is usually launched 60,000$12,000 \mathrm{ft}$ altitude. Depending on filled gas, some highaltitude balloons will remain at a constant height to collect data. The others will be continuously lifted until the balloon explosion. The high-altitude balloon is capable of various objectives, weather balloon, telecommunication balloon, science research balloon and navigation balloon are some typical categories. Structure of high-altitude balloon is simple, and most of the components are available off-the-shelf. As a result, the manufacture is at low cost. Due to these features, some education institutes and students launch high-altitude balloons to execute science experiments and engineering tasks.

As the environments at balloon-launching altitude and low-earth-orbit are similar in some aspect, for low-earthorbit satellite developers, the high-altitude balloon can be used to make an early test for satellite devices. However, there are some critical differences between low-earth orbit and high-altitude environments. The altitude of low-earthorbit is $300 \mathrm{~km}$. When the elevation is over $160 \mathrm{~km}$, the impact of the atmosphere on air drag and radiation are weakened to a negligible-level. In result of this, heat conduction and convection between satellite and air do not exist anymore while the effect of heat radiation dramatically increases. Besides, orbit period of the lowearth-orbit satellite is approximately 84 to 127 minutes. Short period results in rapid temperature change on satellite surface. In result of this, both superheating and undercooling might occur due to fast heat transfer [1]. Compared to low-earth-orbit, the environment at highaltitude is simpler. The high-altitude balloon remains in the stratosphere (below $9 \mathrm{~km}$ ) during the whole lifting process. As shown in Figure 2, the temperature in stratosphere linearly decreases when altitude increases [2]. From temperature indication in the figure, the highaltitude balloon will only suffer the undercooling condition. Moreover, atmosphere effect is still significant at high altitude, which means heat radiation, convection and conduction are all critical.

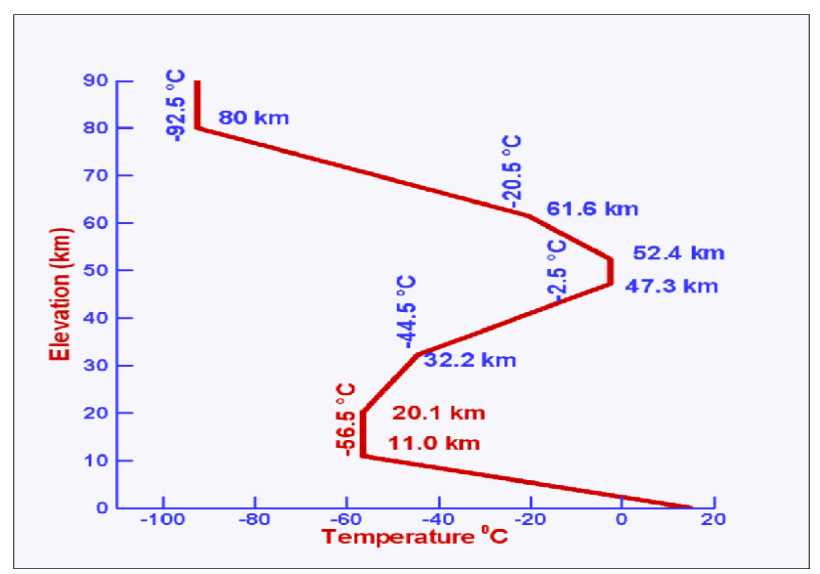

Fig. 2. Atmospheric Temperature at Different Altitudes

Electronic components require appropriate temperature ranges to guarantee high working efficiency and extended durability. The temperature ranges of different elements are specified. Compared to other electrical components, the battery is relatively the most impressible one, the required temperature range is between $-5^{\circ} \mathrm{C}$ and $20^{\circ} \mathrm{C}$. To secure the successful work and long durability of battery in the undercooling or overheating environment, BTC is essential to maintain a proper temperature.

\section{Results Retrieved from Customer Domain and Functional Domain}

Before the axiomatic design was applied, information concerning customer domain and the functional domain was gathered, which was essential to formulate the concept domain. To collect the customer reviews, interviews were done with power system leader, finance administrator and all significant members of the balloon team. The gathered customer needs $(\mathrm{CNs})$ were summarised as:

- $\mathrm{CN}_{1}$ : The BTC should maintain the battery temperature no lower than $5^{\circ} \mathrm{C}$ before the altitude reaches $18,000 \mathrm{~m}$.

- $\mathrm{CN}_{2}$ : The BTC should have a heating region to simulate the overheating condition. A corresponding cooling system should be installed as an early test for the low-earth-orbit cubesat battery cooling system. This cooling system was constrained to be a passive system.

- $\mathrm{CN}_{3}$ : The cooling system should maintain the thermal carrier temperature of heat region no higher than $20^{\circ} \mathrm{C}$.

- $\mathrm{CN}_{4}$ : The BTC should minimise power consumption. Meanwhile, it must automatically shut down when 
the left battery power was less than $30 \%$ to guarantee the work of GPS system.

- $\mathrm{CN}_{5}$ : The BTC should work only during the lifting session.

- $\mathrm{CN}_{6}$ : The BTC electrical system should be compatible with the original $\mathrm{PCB}$ in balloon payload.

- $\quad \mathrm{CN}_{7}$ : The BTC should be controlled by CPU on the original $\mathrm{PCB}$ in balloon payload.

- $\quad \mathrm{CN}_{8}$ : The new PCB of BTC should be no larger than $10 \mathrm{~cm} \times 10 \mathrm{~cm}$.

- $\quad \mathrm{CN}_{9}$ : The total dimensions of BTC and original PCB should be no larger than $12 \mathrm{~cm} \times 25 \mathrm{~cm} \times 10 \mathrm{~cm}$.

- $\mathrm{CN}_{10}$ : All components required to build the BTC should be available off-the-shelf.

- $\mathrm{CN}_{11}$ : The budget should be within an acceptable range.

- $\mathrm{CN}_{12}$ : Ease of the manufacturer should be maximised.

Correspondingly, the functional hierarchy was made as shown in Figure 3. The bottom-level FRs were:

- $\quad \mathrm{FR}_{1.1}$ : Detect the temperature of battery surface with a range of $10-80^{\circ} \mathrm{C}$ and less than $2^{\circ} \mathrm{C}$ tolerance.

- $\mathrm{FR}_{1.2}$ : Detect the left battery volume under the temperature between $-20-80^{\circ} \mathrm{C}$ and the tolerance should be less than $10 \%$.

- $\quad \mathrm{FR}_{1.3}$ : Detect the acceleration of battery under -20$80^{\circ} \mathrm{C}$ with $2 \mathrm{~g}$ sensitivity.

- $\mathrm{FR}_{1.4}$ : Communicate with the central processor to transfer detected information every $0.1 \mathrm{~s}$.

- $\mathrm{FR}_{2.1 .1}$ : Heat up the battery to maintain battery surface temperature at $30^{\circ} \mathrm{C}$ in $-10^{\circ} \mathrm{C}$ environment.

- $\mathrm{FR}_{2.1 .2}$ : Preserve the temperature with thermal insulation material of which the thermal conductivity is no more than $0.12 \mathrm{~W} / \mathrm{mK}$ under room temperature.
- $\quad \mathrm{FR}_{2.2 .1}$ : Create a heat region which could remain at $50{ }^{\circ} \mathrm{C}$ in $10^{\circ} \mathrm{C}$ environment.

- $\quad \mathrm{FR}_{2.2 .2}$ : Cooling down the region to make it no higher than $30^{\circ} \mathrm{C}$ under $50^{\circ} \mathrm{C}$.

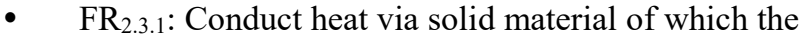
thermal conductivity is higher than $225 \mathrm{~W} / \mathrm{mK}$.

- $\quad \mathrm{FR}_{2.3 .2}$ : Conduct the heat via the surface gap with the liquid conductor of which the thermal conductivity was higher than $6 \mathrm{~W} / \mathrm{mK}$.

- $\quad \mathrm{FR}_{3.1}$ : Terminate heating system within $0.5 \mathrm{~s}$ when the temperature is higher than $15^{\circ} \mathrm{C}$.

- $\quad \mathrm{FR}_{3.2}$ : Terminate heat region within $0.5 \mathrm{~s}$ when the temperature is higher than $50^{\circ} \mathrm{C}$.

- $\quad \mathrm{FR}_{3.3}$ : Trigger and terminate the thermal controller within $0.5 \mathrm{~s}$. Trigger it after balloon starts to lift. Terminate it after the balloon explosion or battery has less than $30 \%$ power left.

- $\quad$ FR $_{4.1}$ : Connect the electrical system to payload PCB within $10 \mathrm{~cm} \times 20 \mathrm{~cm}$ PCB size in total.

- $\quad$ FR $_{4.2}$ : Integral the mechanical system together and compress the dimensions within $12 \mathrm{~cm} \times 25 \mathrm{~cm} \times$ $10 \mathrm{~cm}$.

In addition to the FRs list, another discussion was made with mentioned stakeholders. With their opinions on the priority of FRs, a classification table was made based on Kano Customer model and House of Quality (HOQ). The result indicated that the following five FRs were relatively more important. Analysis of these five FRs will be highlighted in the following axiomatic design.

- $\quad \mathrm{FR}_{2.1 .1}$ : Heat up the battery to maintain battery surface temperature at $30^{\circ} \mathrm{C}$ in $-10^{\circ} \mathrm{C}$ environment.

- $\mathrm{FR}_{2.1 .2}$ : Preserve the temperature with thermal insulation material of which the thermal conductivity is no more than $0.12 \mathrm{~W} / \mathrm{mK}$ under room temperature.

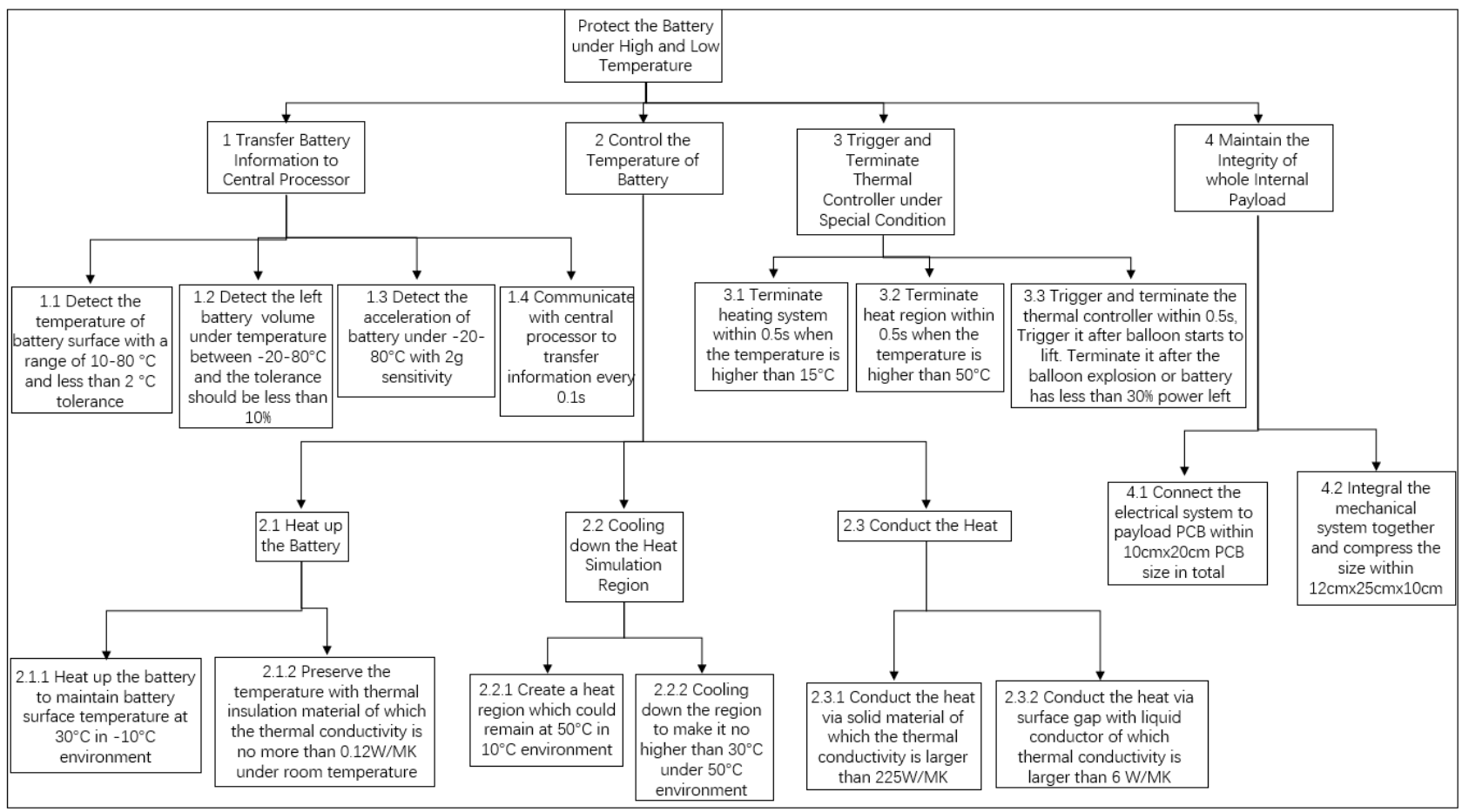

Fig. 3. Functional Hierarchy of BTC 
- $\mathrm{FR}_{2.2 .2}$ : Cooling down the region to make it no higher than $30^{\circ} \mathrm{C}$ under $50^{\circ} \mathrm{C}$.

- $\quad \mathrm{FR}_{2.3 .1}$ : Conduct heat via solid material of which the thermal conductivity is higher than $225 \mathrm{~W} / \mathrm{mK}$.

- $\quad \mathrm{FR}_{2.3 .2}$ : Conduct the heat via the surface gap with the liquid conductor of which the thermal conductivity was higher than $6 \mathrm{~W} / \mathrm{mK}$.

It should be noticed that those FRs were the modified results based on independence axiom design feedback. The initial FRs were checked to be dependent according to concept organisation procedures. Some typical changes would be emphasised in independence axiom design part.

\section{The Axiomatic Design of BTC}

\subsection{DPs Generation and Composing}

For each bottom-level FRs, three alternative DPs were generated to compose candidate BTC concepts. Although there would be a relatively most proper concept, all three DPs were supposed to satisfy CNs in special situations. The five significant FRs mentioned in forewords were specially analysed, while others were briefly summarised.

For battery heating $\left(\mathrm{FR}_{2.1 .1}\right)$, as the BTC was based on an electrical system, chips resistors matrix can be a proper solution, especially chip resistors were available in bulk. Moreover, chip resistor had long durability and high tolerance to temperature, which will increase the stability of the heater. Apart from chip resistors, nichrome wire had already been used to develop heater elements by some amateurs due to simple manufacture on PCB. Moreover, inspired by computer $\mathrm{CPU}$ and electromagnetic oven, a simplified high-frequency heater could be an alternative option. As the battery provides DC power, necessary $\mathrm{DC} / \mathrm{AC}$ converting components are essential as assistance.

For temperature preservation $\left(\mathrm{FR}_{2.1 .2}\right)$, several categories of materials had been applied as thermal insulation in different industrial sectors. For instances, the polymer-ceramic composite was a common thermal insulation material for architecture exterior wall and fire belt [3]. Meanwhile, Special categories of phenolic resin and epoxy resin had been developed by oil companies to preserve heat for steel pipes [4]. Glass wool could be another option, which had been utilised to maintain temperature for hot water pipes [5].

For cooling system( $\left.\mathrm{FR}_{2.2 .2}\right)$, as it was mentioned in customer domain part, the cooling system was constrained to be a passive system. There were some well-developed cooling system concepts available. Cooling fins were commonly used in the laptop. The heat sink was applied to Raspberry Pi 3 Model B. Special heat radiation coat has been applied on satellite.

For heat conduction via the solid material $\left(\mathrm{FR}_{2.3 .1}\right), \mathrm{CN}_{10}$ and $\mathrm{CN}_{11}$ required that all materials should be available off-the-shelf at an acceptable price, in this case, some advanced materials like graphene film and carbide would not be considered. Among those familiar metals, aluminium, copper and silver had significantly higher thermal conduction coefficients which had been wellutilised on computers [6]. To save cost, silver would be replaced by silver plated copper.
For heat conduction via the surface gap $\left(\mathrm{FR}_{2.3 .2}\right)$, the DP is applied to battery-heating system contacting surface and heating region-cooling system contacting surface. Referring to CPU-heat pipe contacting surface and GPUheat pipe contact surface in laptops, thermal metal compound, silicone thermal compound and metal oxide thermal grease were selected to satisfy this FR.

All candidate DPs of each FRs were shown as a Morphological Chart in Table 1. To generate candidate composed concepts, all candidate DPs were divided into three groups to form three candidate concepts. An assessment was made to evaluate feasibility and competence of compose. The candidate DPs and three concepts were indicated in different Rome number. Concept 1 was represented by I, concept 2 was represented by II, and concept 3 was represented by III.

In this procedure, one challenge for the student was coming up valid candidate DPs. In engineering design education, students might not be familiar with the chosen design project. In this condition, online search might be the common way to find enough candidate DPs. Random search is ineffective, educators should apply strategies, which help students with accurate information search.

Table 1. Morphological Chart of BTC

\begin{tabular}{|c|c|c|c|}
\hline FRs & DP1 & DP2 & DP3 \\
\hline $\mathrm{FR}_{1.1}$ & $\begin{array}{l}\text { A/D Output } \\
\text { Thermal } \\
\text { Sensor }(\mathrm{I})\end{array}$ & $\begin{array}{c}\text { NTC } \\
\text { Thermistor } \\
\text { (II) }\end{array}$ & $\begin{array}{c}\text { Resistance } \\
\text { Temperature } \\
\text { Detector (III) }\end{array}$ \\
\hline $\mathrm{FR}_{1.2}$ & $\begin{array}{c}\text { Battery Fuel } \\
\text { Gauge (I) }\end{array}$ & $\begin{array}{l}\text { Current Sense } \\
\text { Resistor with } \\
\text { OPA (II) }\end{array}$ & $\begin{array}{l}\text { Capacitance } \\
\text { Meter (III) }\end{array}$ \\
\hline $\mathrm{FR}_{1.3}$ & $\begin{array}{c}\text { Accelerometer } \\
\text { with Analog } \\
\text { Voltage } \\
\text { Output (II) }\end{array}$ & $\begin{array}{c}\text { Digital } \\
\text { Accelerometer } \\
\text { (I) }\end{array}$ & $\begin{array}{c}\mathrm{A} / \mathrm{D} \\
\text { Accelerometer } \\
\text { (III) }\end{array}$ \\
\hline $\mathrm{FR}_{1.4}$ & $\mathrm{I} 2 \mathrm{C}(\mathrm{I})$ & SPI (II) & PCI (III) \\
\hline $\mathrm{FR}_{2.3 .1}$ & $\begin{array}{l}\text { Aluminium } \\
\text { (II) }\end{array}$ & Copper (I) & $\begin{array}{l}\text { Silver Plated } \\
\text { Copper (III) }\end{array}$ \\
\hline $\mathrm{FR}_{2.3 .2}$ & $\begin{array}{c}\text { Metal } \\
\text { Thermal } \\
\text { Compound } \\
\text { (III) }\end{array}$ & $\begin{array}{c}\text { Silicone } \\
\text { Thermal } \\
\text { Compound } \\
\text { (II) }\end{array}$ & $\begin{array}{c}\text { Metal Oxide } \\
\text { Thermal } \\
\text { Grease (I) }\end{array}$ \\
\hline $\mathrm{FR}_{2.1 .1}$ & $\begin{array}{c}\text { Heating } \\
\text { Region } \\
\text { Combined by } \\
\text { Small-Value } \\
\text { Resistors 1 (I) }\end{array}$ & $\begin{array}{c}\text { Heating } \\
\text { Elements } \\
\text { Assembled by } \\
\text { Nichrome } \\
\text { Wire } 1 \text { (II) }\end{array}$ & $\begin{array}{c}\text { High- } \\
\text { Frequency } \\
\text { Heater } 1 \text { (III) }\end{array}$ \\
\hline $\mathrm{FR}_{2.1 .2}$ & $\begin{array}{l}\text { Polymer- } \\
\text { Ceramic } \\
\text { Composite } \\
\text { Thermal } \\
\text { Cover (I) }\end{array}$ & $\begin{array}{c}\text { Phenolic } \\
\text { Resin Cover } \\
\text { (III) }\end{array}$ & $\begin{array}{l}\text { Glass Wool } \\
\text { (II) }\end{array}$ \\
\hline $\mathrm{FR}_{2.2 .1}$ & $\begin{array}{c}\text { Heating } \\
\text { Region } \\
\text { Combined by } \\
\text { Small-Value } \\
\text { Resistors } 2 \text { (I) }\end{array}$ & $\begin{array}{c}\text { Heating } \\
\text { Elements } \\
\text { Assembled by } \\
\text { Nichrome } \\
\text { Wire } 2 \text { (II) }\end{array}$ & $\begin{array}{c}\text { High- } \\
\text { Frequency } \\
\text { Heater } 2 \text { (III) }\end{array}$ \\
\hline $\mathrm{FR}_{2.2 .2}$ & $\begin{array}{l}\text { Cooling Fins } \\
\text { (III) }\end{array}$ & $\begin{array}{c}\text { Metal Heat } \\
\text { Sink (I) }\end{array}$ & $\begin{array}{l}\text { Dissipation } \\
\text { Coating (II) }\end{array}$ \\
\hline $\mathrm{FR}_{3.1}$ & $\begin{array}{c}\text { Active or } \\
\text { Sleeping } \\
\text { Mode of I/O } \\
\text { Expander Pin } \\
1 \text { (II) }\end{array}$ & $\begin{array}{c}\text { Analog } \\
\text { Switch } 1 \text { (III) }\end{array}$ & $\begin{array}{c}\text { Low-Mode } \\
\text { Power Input } \\
\text { via I/O } \\
\text { Expander } 1 \text { (I) }\end{array}$ \\
\hline
\end{tabular}




\begin{tabular}{|c|c|c|c|}
\hline $\mathrm{FR}_{3.2}$ & $\begin{array}{c}\text { Active or } \\
\text { Working } \\
\text { Mode of I/O } \\
\text { Expander Pin } \\
2 \text { (II) }\end{array}$ & $\begin{array}{c}\text { Analog } \\
\text { Switch } 2 \text { (III) }\end{array}$ & $\begin{array}{c}\text { Low-Mode } \\
\text { Power Input } \\
\text { via I/O } \\
\text { Expander } 2 \text { (I) }\end{array}$ \\
\hline $\mathrm{FR}_{3.3}$ & $\begin{array}{l}\text { Pin-Mode on } \\
\text { Central } \\
\text { Processor } \\
\text { Unit (I) } \\
\end{array}$ & $\begin{array}{c}\text { IC Signal } \\
\text { Switch (III) }\end{array}$ & $\begin{array}{l}\text { Resettable } \\
\text { Fuse (II) }\end{array}$ \\
\hline $\mathrm{FR}_{4.1}$ & $\begin{array}{c}\text { One Single } \\
\text { PCB Shared } \\
\text { by BTC and } \\
\text { Original PCB } \\
\text { (II) }\end{array}$ & $\begin{array}{c}\text { Double } \\
\text { Layers } \\
\text { Structure } \\
\text { Fixed by } \\
\text { Standoffs (I) }\end{array}$ & $\begin{array}{c}\text { Two } \\
\text { Independent } \\
\text { PCB(Flexible } \\
\text { Structure) (III) }\end{array}$ \\
\hline $\mathrm{FR}_{4.2}$ & $\begin{array}{l}\text { Internal wire } \\
\text { connection } \\
\text { (II) }\end{array}$ & $\begin{array}{l}\text { Connection } \\
\text { with Headers } \\
\text { (I) }\end{array}$ & $\begin{array}{l}\text { External wire } \\
\text { connection } \\
\text { (III) }\end{array}$ \\
\hline
\end{tabular}

\subsection{Concept Organisation and Visualisation}

To reduce complexity and increase feasibility, functional dependency should be minimised. Three FR-DP hierarchies were used to evaluate functional dependence for all three concepts. Each FR was assessed to check if other DPs were required to execute the function apart from their corresponding DPs. Once decouple design existed, the relevant current candidate DPs would be replaced by alternative concepts to achieve uncouple design. If this step was not applicable, corresponding FR would be checked whether it was broken down to bottomlevel. If uncouple design still could not be generated, corresponding customer demand would be reviewed to modify the FR. After several adjustments, the final adjusted FR-DP matrixes of three concepts were indicated in Figure 4,5 and 6.

Some typical changes through this feedback process should be emphasised. Initially, heat conduction was not divided into $\mathrm{FR}_{2.3 .1}$ and $\mathrm{FR}_{2.3 .2}$, when Morphological Chart was firstly generated, it was found that heat conduction required both solid and liquid thermal conduction material to achieve. Considering this, 'conducting heat' was evaluated as 'not broken down to bottom-level', which led to $\mathrm{FR}_{2.3 .1}$ and $\mathrm{FR}_{2.3 .2}$. Another typical change was BTC triggering and termination. Initially, terminating and triggering system were classified based on execution conditions, for example, three FRs were generated at first as the heating system should be discontinued when the temperature was higher than $15^{\circ} \mathrm{C}$, battery power was lower than $30 \%$ or after balloon explosion. In result of this FRs generation outcome, the three FRs could be executed by only one or two DPs, which caused a regional coupled design. Those FRs were combined into $\mathrm{FR}_{3.1}$ and $\mathrm{FR}_{3.2}$ eventually to formulate the current uncoupled design. The similar issue happened to information transferring as well, $\mathrm{FR}_{1.4}$ was initially three $\mathrm{FRs}$ which corresponded to information transferring of $\mathrm{FR}_{1.1}, \mathrm{FR}_{1.2}$ and $\mathrm{FR}_{1.3}$, noticed that those were executed by I2C/SCL/PCI this single DP, those FRs were combined into current $\mathrm{FR}_{1.4}$.

Three corresponding concept visualisations were made according to the Morphological Chart, which were shown in Figure 7,8 and 9. These visualisations were illustrative, and the real product might differ. Some DPs were based on the original balloon PCB, which contained a Raspberry Pi Mini as CPU and detection sensors. DPs and corresponding FRs were annotated in visualisation figures as well.

\subsection{Concept Selection}

In this section, the information axiom design was applied to select the relatively most proper concept. At first, candidate DPs of each FRs were evaluated, analysis of the five most important FRs would be clarified, others would be briefly summarised. The final result would be out of the Pugh's Matrix. It should be pointed out that due to lack

\begin{tabular}{|c|c|c|c|c|c|c|c|c|c|c|c|c|c|c|c|}
\hline Concept 1 & 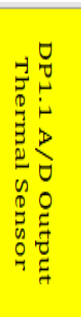 & 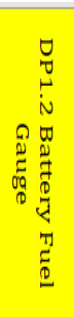 & 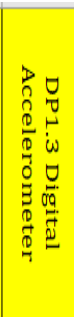 & 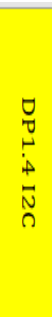 & 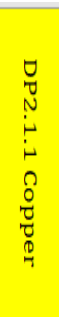 & 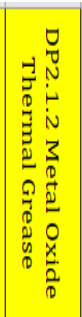 & 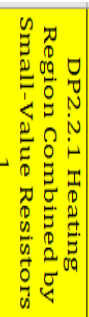 & 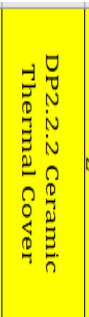 & 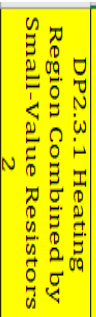 & 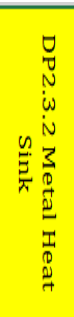 & 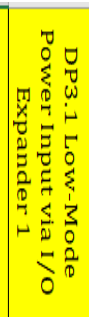 & 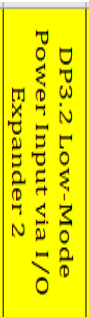 & 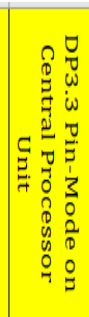 & 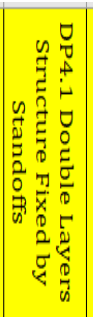 & 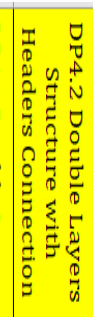 \\
\hline \multicolumn{16}{|l|}{1.1 Detect the Temperature of Battery Surface } \\
\hline \multicolumn{16}{|l|}{1.2 Detect the Left Power of Battery } \\
\hline \multirow{2}{*}{\multicolumn{16}{|c|}{$\frac{1.3 \text { Detect the Acceleration of Battery }}{14 \text { Communicate with Central Processor }}$}} \\
\hline 1.4 Communicate with Central Processor & & & & & & & & & & & & & & & \\
\hline \multirow{2}{*}{\multicolumn{16}{|c|}{$\begin{array}{l}2.1 .1 \text { Heat up the Battery } \\
212 \text { Presenve the Temperature }\end{array}$}} \\
\hline & & & & & & & & & & & & & & & \\
\hline \multicolumn{16}{|l|}{$\begin{array}{l}\text { 2.1.2 Preserve the Temperature } \\
\text { 2.2.1 Create a Heat Region }\end{array}$} \\
\hline \multicolumn{16}{|l|}{ 2.2.2 Cooling down the Region } \\
\hline \multirow{2}{*}{\multicolumn{16}{|c|}{$\begin{array}{l}23.1 \text { Conduct the heat via solid material } \\
2.32 \text { Conduct the heat via surface oaro }\end{array}$}} \\
\hline & & & & & & & & & & & & & & & \\
\hline \multicolumn{16}{|l|}{ 3.1. Terminate Heating System } \\
\hline \multirow{2}{*}{\multicolumn{16}{|c|}{$\begin{array}{l}\text { 3.2 Terminate Cooling System } \\
\text { 3.3 Triocer Terminate the Thermal Controller }\end{array}$}} \\
\hline \multirow{2}{*}{\multicolumn{16}{|c|}{$\begin{array}{l}\text { 3.3 Trigger Terminate the Thermal Controller } \\
\text { 4.1 Connect the Electrical Sustem to Pavload PCB }\end{array}$}} \\
\hline & & & & & & & & & & & & & & & \\
\hline 4.2 Integral the Mechanical System together & & & & & & & & & & & & & & & \\
\hline
\end{tabular}

Fig. 4. FR-DP Matrix of Concept 1 


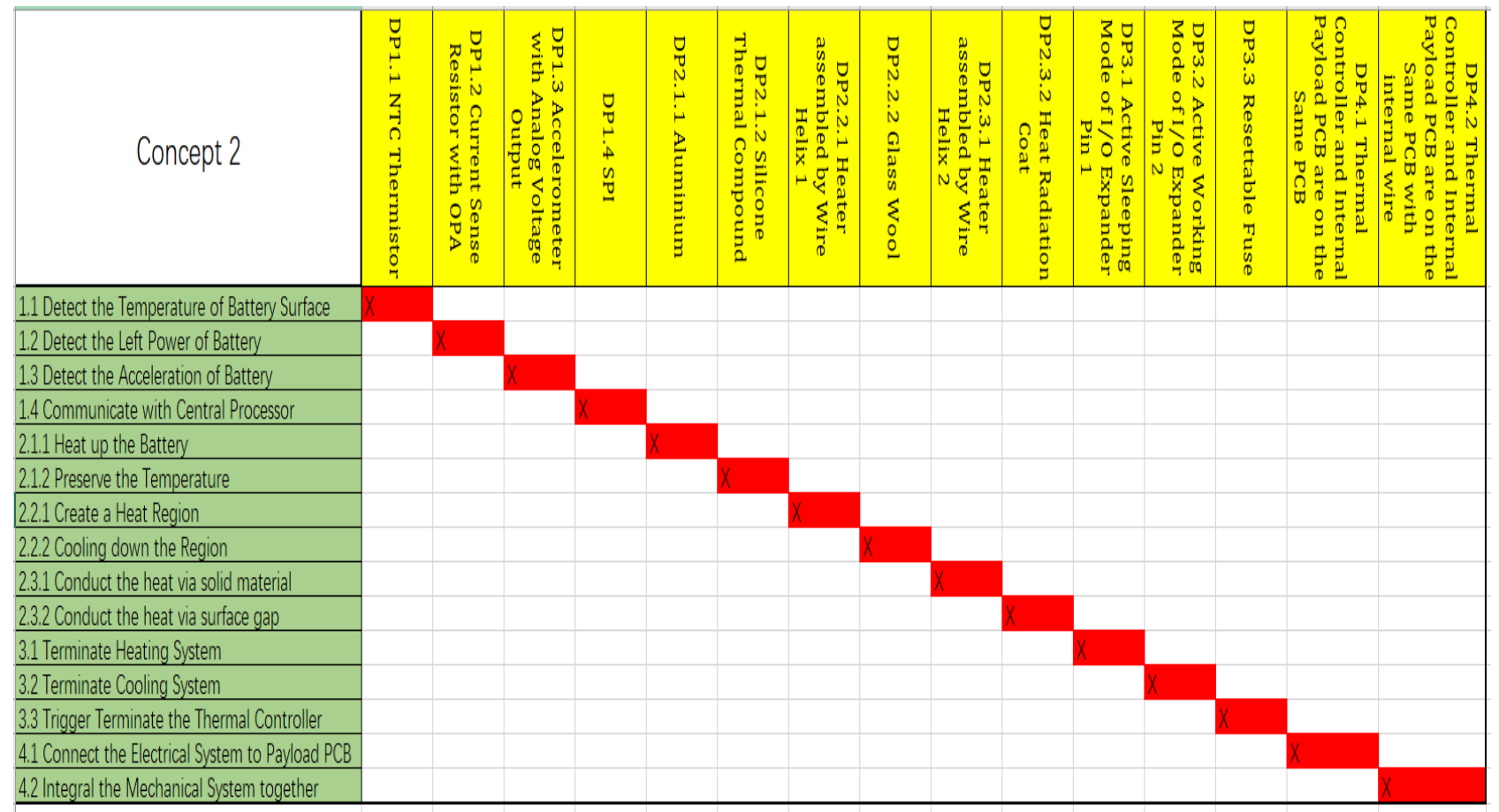

Fig. 5. FR-DP Matrix of Concept 2

of test apparatus and relevant research information, all the concept evaluations were based on similar condition tests, past relevant research results, inspiration from similar FRDP of other products and some essential environmental assumptions, which made the whole evaluation a rough result. This would be discussed later.

For the $\mathrm{FR}_{2.1 .1}$, Li-ion battery was applied to power the whole system. When the temperature was below $10^{\circ} \mathrm{C}$, the charge-transfer resistance of battery would start to rapidly decrease while bulk resistance and layer resistance was still in an acceptable range [7]. According to the temperature recording from previous balloon test data, the whole lifting process lasted for 61 minutes, the period when the temperature was below $-10^{\circ} \mathrm{C}$ just lasted for 12 minutes. As BTC was expected to be the most power-consuming system in balloon payload, while heat transferred more rapidly when temperature difference was higher [8], out of the consideration to save battery power, $-10^{\circ} \mathrm{C}$ was determined as the threshold above which battery temperature should be maintained at a proper range. Meanwhile, $20^{\circ} \mathrm{C}$ should be the maximum proper temperature for battery working. In result of these, 'maintain the temperature at $20^{\circ} \mathrm{C}$ in $-10^{\circ} \mathrm{C}$ environment' should be the ideal demand value for $\mathrm{FR}_{2.1 .1}$. However, the real environment might be much more complex than the theoretical hypothesis, to guarantee the competent

\begin{tabular}{|c|c|c|c|c|c|c|c|c|c|c|c|c|c|c|c|}
\hline Concept 3 & 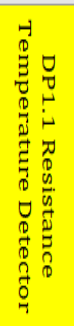 & 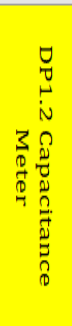 & 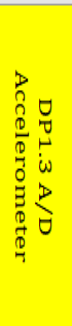 & $\begin{array}{l}\nabla \\
0 \\
+ \\
i \\
0 \\
\Omega\end{array}$ & 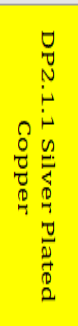 & 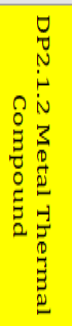 & 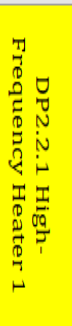 & 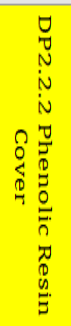 & 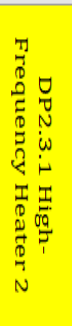 & 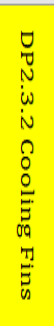 & 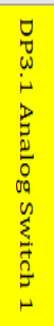 & 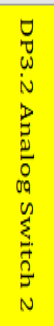 & 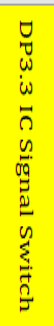 & 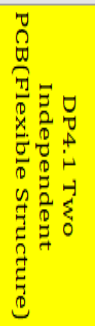 & 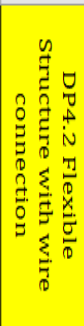 \\
\hline \multicolumn{16}{|l|}{1.1 Detect the Temperature of Battery Surface } \\
\hline \multicolumn{16}{|l|}{1.2 Detect the Left Power of Battery } \\
\hline \multicolumn{16}{|l|}{1.3 Detect the Acceleration of Battery } \\
\hline \multicolumn{16}{|l|}{1.4 Communicate with Central Processor } \\
\hline \multicolumn{16}{|l|}{ 2.1.1 Heat up the Battery } \\
\hline \multicolumn{16}{|l|}{ 2.1.2 Preserve the Temperature } \\
\hline \multicolumn{16}{|l|}{ 2.2.1 Create a Heat Region } \\
\hline \multicolumn{16}{|l|}{ 2.2.2 Cooling down the Region } \\
\hline \multicolumn{16}{|l|}{ 2.3.1 Conduct the heat via solid material } \\
\hline \multicolumn{16}{|l|}{ 2.3.2 Conduct the heat via surface gap } \\
\hline \multicolumn{16}{|l|}{ 3.1 Terminate Heating System } \\
\hline \multicolumn{16}{|l|}{ 3.2 Terminate Cooling System } \\
\hline \multicolumn{16}{|l|}{ 3.3 Trigger Terminate the Thermal Controller } \\
\hline 4.1 Connect the Electrical System to Payload PCB & & & & & & & & & & & & & & & \\
\hline 4.2 Integral the Mechanical System together & & & & & & & & & & & & & & & \\
\hline
\end{tabular}

Fig. 6. FR-DP Matrix of Concept 3 


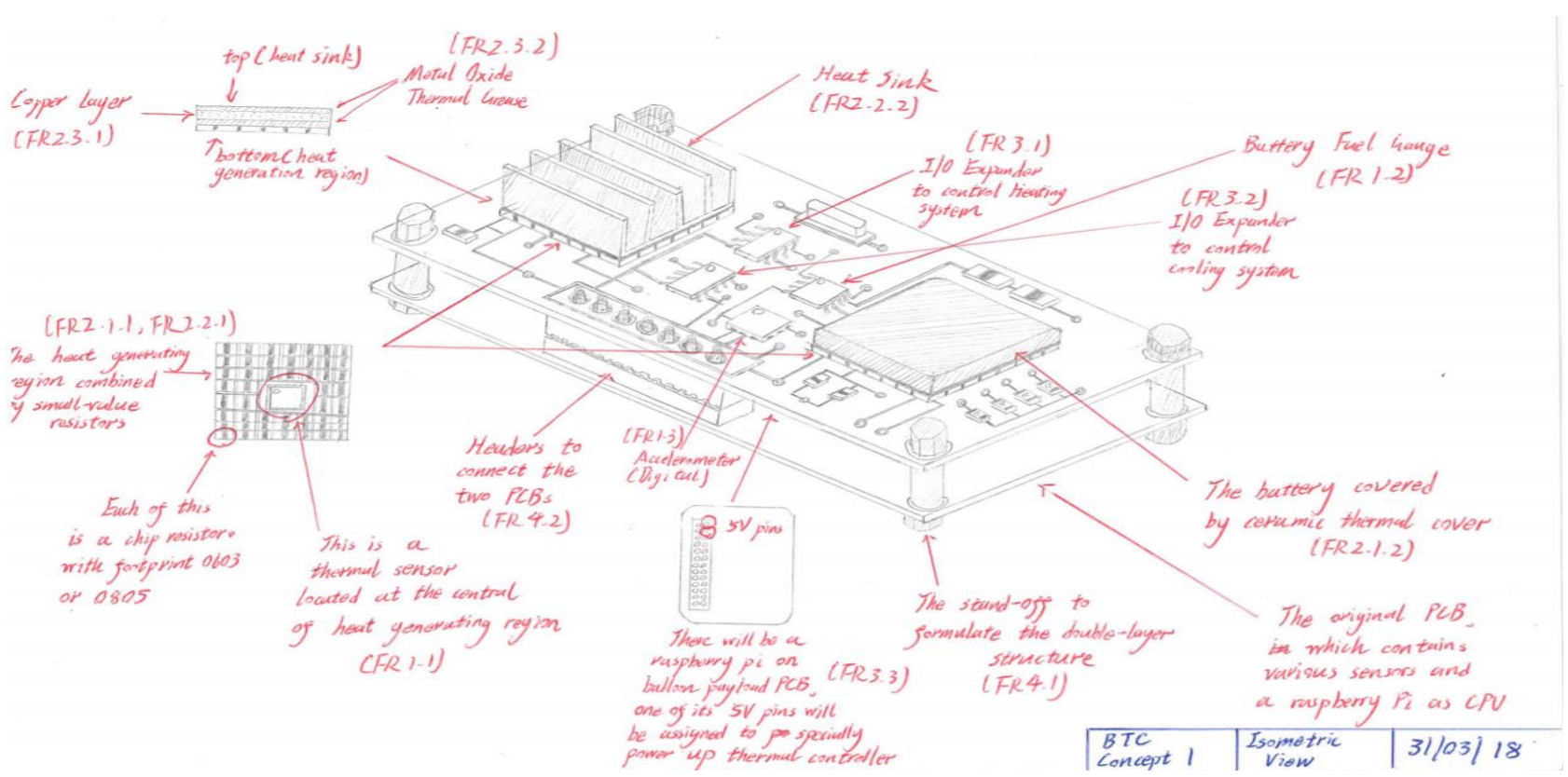

Fig. 7. Visualisation of Concept 1

performance, required maintained temperature was increased to $30^{\circ} \mathrm{C}$. To make a rough estimation of concepts performance, two simple prototypes were made to test small-value resistors matrix and high-frequency heaters. The small-value resistors matrix was based on a previous obsolete $\mathrm{PCB}$ which contained a $3 \times 30805$ footprints matrix. A $10 \mathrm{~V}$ DC power generator was used as power source. Meanwhile, 20 turns copper wire loops, and a short copper stick were used together to make a simple high-frequency heater, which was powered by $10 \mathrm{~V}$ AC 5KHz. Detecting surface of a temperature sensor was attached to resistors surface and end of the copper stick to detect temperature. An Arduino Uno was used to receive the signal from the temperature sensor. A freezer was applied to achieved $5^{\circ} \mathrm{c}$ environment. The tests results indicated that temperature of small-value resistors matrix vibrated between $26^{\circ} \mathrm{C}$ to $30^{\circ} \mathrm{C}$, while that of high- frequency heater vibrated between $29^{\circ} \mathrm{C}$ to $36^{\circ} \mathrm{C}$. As for the nichrome wire heat element, a similar test had been made by a senior student in the club. The test was taken under $4^{\circ} \mathrm{C}$, and the nichrome heat element maintained approximately between $43^{\circ} \mathrm{C}$ to $46^{\circ} \mathrm{C}$, the thickness of nichrome wire was chosen as $1 \mathrm{~mm}$ and gap between wires was $0.75 \mathrm{~mm}$. According to the heat transfer equation, when attachment area and thickness of conductor were the same, heat transfer speed was proportional to temperature difference [9]. Based on this, 'maintain between $43^{\circ} \mathrm{C}$ to $46^{\circ} \mathrm{C}$ under $4^{\circ} \mathrm{C}$ ' was equivalent to 'maintain between $34^{\circ} \mathrm{C}$ to $37^{\circ} \mathrm{C}$ under $-5^{\circ} \mathrm{C}$ '. The result of $\mathrm{FR}_{2.1 .1}$ concepts evaluation was shown in Figure 10. One critical problem was that many factors in the real environment and test conditions varied significantly such as pressure difference and power source efficiency, which made this a rough evaluation and might not be valid in actual application.

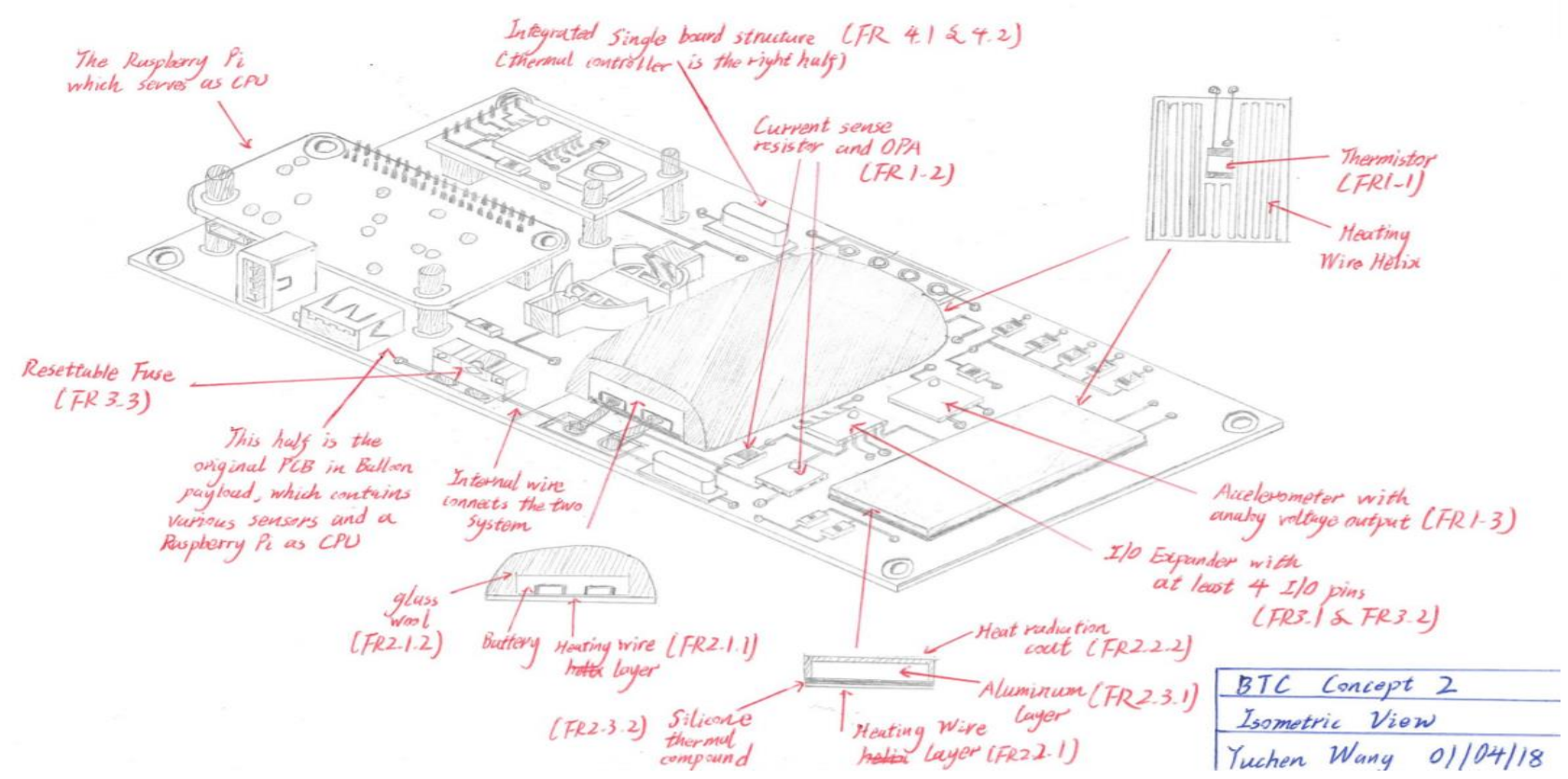

Fig.8. Visualisation of Concept 2 


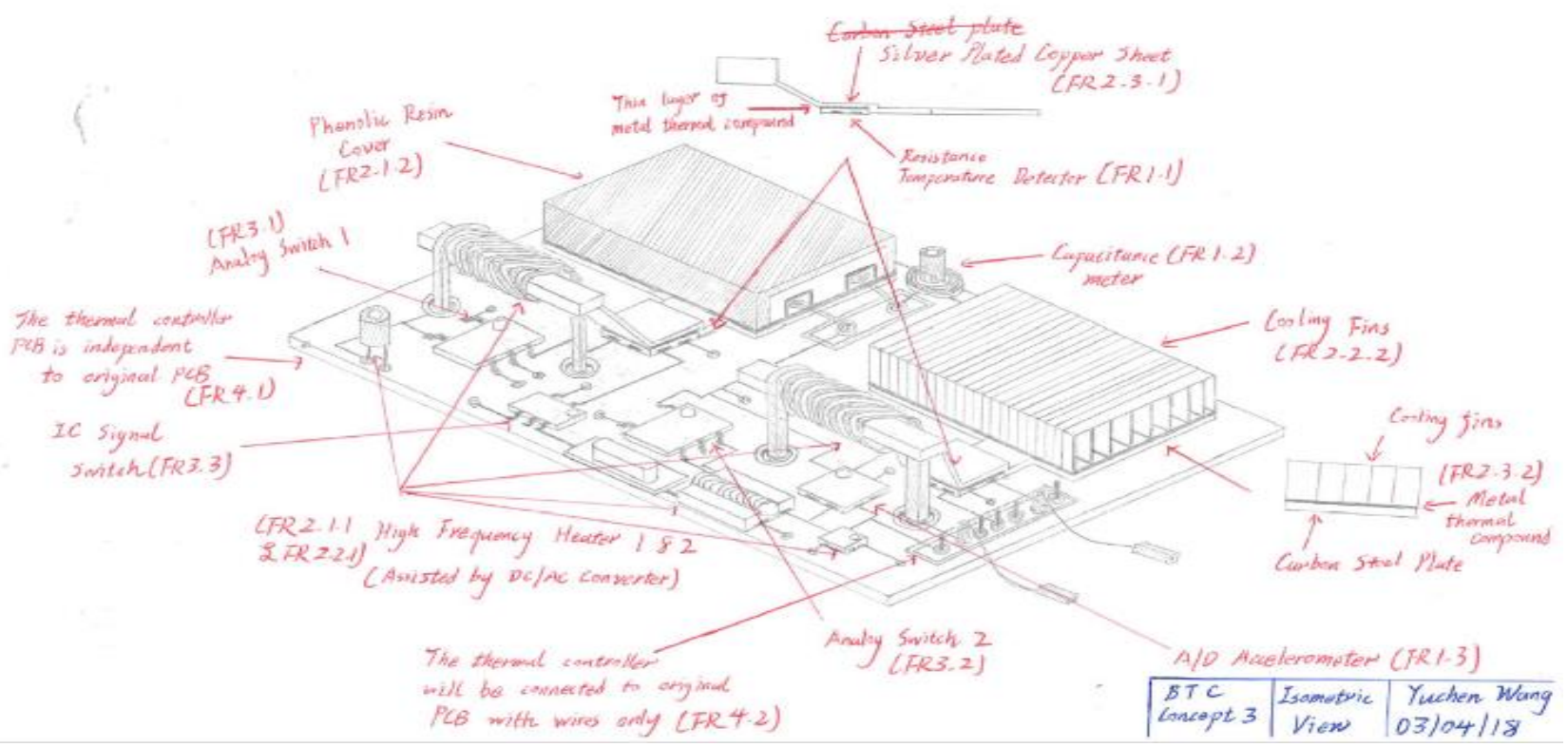

Fig. 9. Concept Visualisation of Concept 3

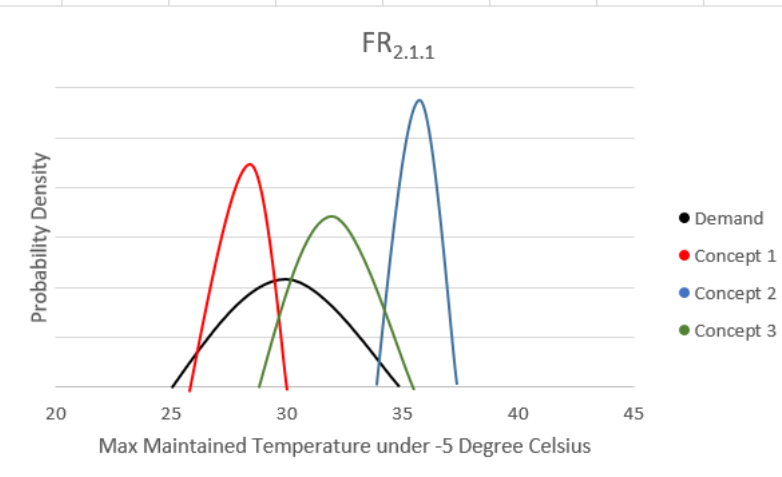

Fig. 10. $P D F$ for $\mathrm{FR}_{2.1 .1}$ Candidate DPs

For $\mathrm{FR}_{2.1 .2}$, currently, the bottom threshold for thermal insulation material was roughly $0.12 \mathrm{~W} / \mathrm{mK}$ as thermal conduction coefficient under room temperature, which determined the fundamental demand of $\mathrm{FR}_{2.1 .2}$. Industrial thermal-insulation material frequently had that around $0.045 \mathrm{~W} / \mathrm{mK}$ [10]. When constraints could be maintained, the thermal conduction coefficient should be as low as possible. For polymer ceramic, the composition could contain $\mathrm{ZrO}_{2}, 3 \mathrm{YSZ}, \mathrm{CeO}_{2}$ and $\mathrm{Al}_{2} \mathrm{O}_{3}$. Some tests had been done under $1273 \mathrm{~K}$ and result indicated that the thermal conduction coefficient was around $1.5-3.5 \mathrm{~W} / \mathrm{mK}$ [11]. Meanwhile, another research stated that thermal conduction coefficient might raise several times for solid and liquid materials [12]. As a result, compositions of solid polymer ceramic roughly had thermal conduction coefficient $0.3-0.7 \mathrm{~W} / \mathrm{mK}$. By adjusting composition proportion, density and internal structure, composed polymer ceramic could be lowered to $0.1 \mathrm{~W} / \mathrm{mK}$. As for glass wool, it accounted for $60 \%$ European market of thermal insulation material for building [5]. Depending on the composition of glass fibres, the thermal conductivity of solid glass wool varied between $0.15-0.26 \mathrm{~W} / \mathrm{mK}$ [13]. Similar to the polymer, industrial-utilised glass fibre had much lower thermal conductivity due to the unique structure and mineral composition, which was around $0.035 \mathrm{~W} / \mathrm{mK}$. In the real application, its performance might be more competent by being stacked. As for phenolic resin, similar to glass wool and polymer-ceramic, the thermal conductivity was significantly affected by fibre structure and composite proportion. For instance, phenolic foam used for building walls had the thermal conductivity at around $0.02 \mathrm{~W} / \mathrm{mK}[14]$. The evaluation of three materials was shown in Figure 11.

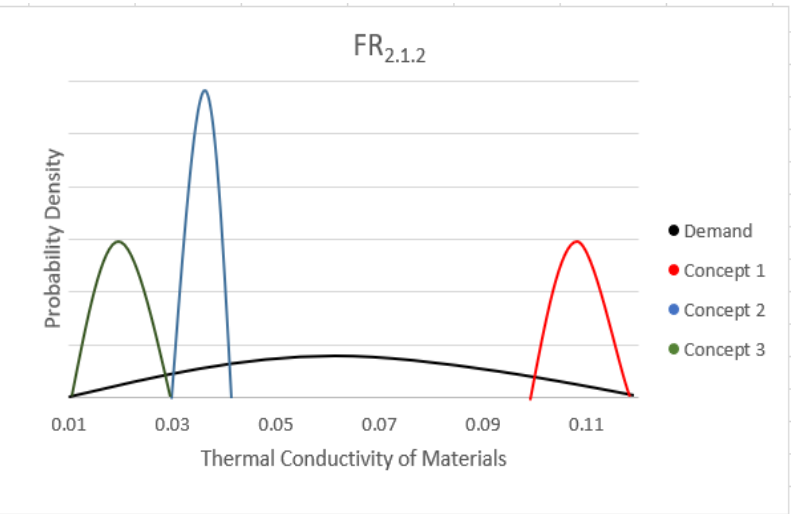

Fig. 11. PDF for $\mathrm{FR}_{2.1 .2}$ Candidate DPs

For $\mathrm{FR}_{2.2 .2}$, the demand value came from coordination to $\mathrm{FR}_{2.2 .1}$. Same DP was used to achieve both $\mathrm{FR}_{2.2 .1}$ and $\mathrm{FR}_{2.1 .1}$. As the low-temperature environment at high altitude would significantly affect the high-temperature maintenance of heat simulation region, the performance of $\mathrm{FR}_{2.2 .2}$ and $\mathrm{FR}_{2.2 .1}$ would be based on low altitude phase. The temperature maintenance requirement for $\mathrm{FR}_{2.2 .1}$ was $50^{\circ} \mathrm{C}$, correspondingly, cooling effect was based on $50^{\circ} \mathrm{C}$ as well. As mentioned in the foreword, $20^{\circ} \mathrm{C}$ or below should be proper to maintain a longer Li-ion battery cycle life, when the temperature was increased to $30^{\circ} \mathrm{C}$, life cycle reduced for approximately $20 \%$ [15], which was 
determined as the bottom-effect threshold. $4^{\circ} \mathrm{C}$ tolerance was allowed for concept effect. For the simple evaluation test, the $3 \times 3$ small-value resistors matrix mentioned in $\mathrm{FR}_{2.1 .1}$ was used to generate high temperature. The model remained between $48^{\circ} \mathrm{C}$ to $51^{\circ} \mathrm{C}$ under room temperature with $10 \mathrm{~V}$ DC power, which roughly satisfied the $50^{\circ} \mathrm{C}$ test requirement. The same temperature sensor and Arduino $\mathrm{UNO}$ in $\mathrm{FR}_{2.1 .1}$ test were applied in this test. A copper metal heat sink of Raspberry 3 Model B was used to test concept 1 . The result indicated that the temperature vibrated between $31^{\circ} \mathrm{C}$ to $33^{\circ} \mathrm{C}$. As for cooling fins, a mini-size aluminium one made by milling machine was applied in the test, which remained between $35^{\circ} \mathrm{C}$ and $36^{\circ} \mathrm{C}$. For the dissipation coating, graphene was chosen as the material. The temperature result was between $40^{\circ} \mathrm{C}$ to $42^{\circ} \mathrm{C}$. The probability density function chart was shown in Figure 12. The test was based on hypothesis such as the temperature of cooling system surface and battery surface were the same. Similar to the $F_{2.1 .1}$ test, differences existed between analysis and real condition as well, which made the evaluation result might be significantly different compared to practical effect. Although concept 2 and 3 were out of demand range, however, concept 2 had relatively lower cost, and concept 3 was more stable, which made them still probably useful for future optimisation.

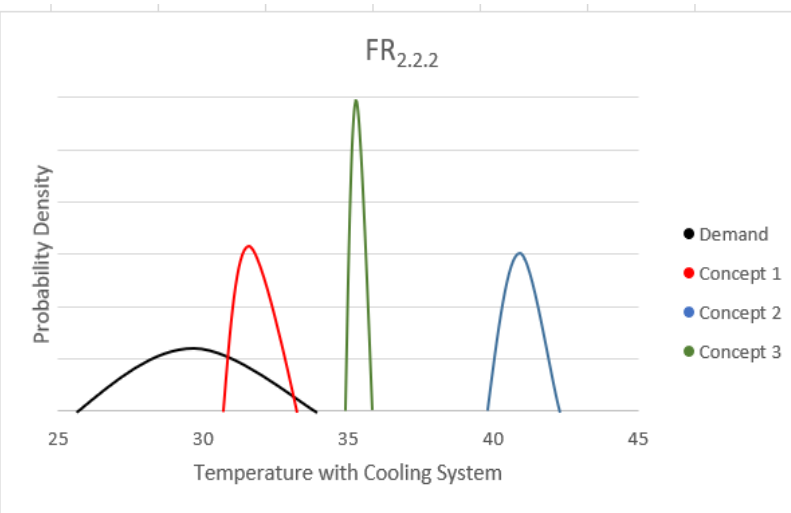

Fig. 12. PDF for $F R_{2.2 .2}$ Candidate DPs

For $\mathrm{FR}_{2.3 .1}$, the evaluation criterion was inspired by laptop cooling fins and heat pipes. The heat conduction system in a laptop was commonly the combination of copper and aluminium. Relatively, copper had better thermal conduction while aluminium benefited heat transferring more. The aluminium applied in laptop cooling fins had thermal conduction coefficient at around $247 \mathrm{~W} / \mathrm{mK}$ while that of copper might reach $398 \mathrm{~W} / \mathrm{mK}$ [15]. Operating temperature and extent of oxidising could impact the thermal conduction. Considering that the internal temperature of laptop CPU could reach $80^{\circ} \mathrm{C}$ which was higher than test demand, the demand value of thermal conductivity could be slightly lower than that of aluminium used in the laptop. In this case, thermal conduction coefficient of ordinary high-purity aluminium was chosen as lowest evaluation threshold which was $225 \mathrm{~W} / \mathrm{mK}$. Within an acceptable cost range, thermal conductivity should be the higher, the better. For concept 3 , silver was one of the best heat conduction material. However, its price was much higher than pure copper while thermal conduction increasing was limited. Considering this, silver plated copper was selected to replace pure silver. According to the database, the probability density function evaluation was indicated in Figure 13.

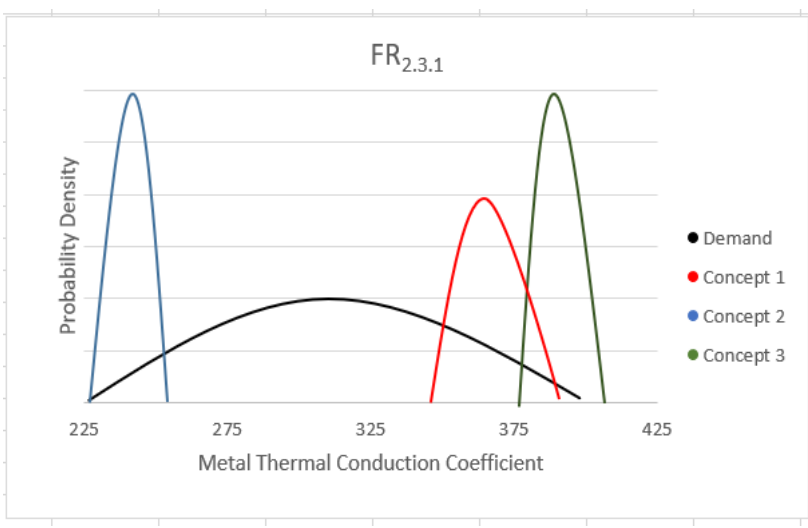

Fig. 13. $P D F$ for $F R_{2.3 .1}$ Candidate DPs

For $\mathrm{FR}_{2.3 .2}$, some extra information should be introduced at first. The thermal conduction coefficients of metals were commonly higher than $100 \mathrm{~W} / \mathrm{mK}$, while that of air was $0.029 \mathrm{~W} / \mathrm{mK}$ under room temperature [15]. Theoretically, if the contact surfaces of metals were perfectly flat, thermal conductivity would reach maximum. However, metal surface was rough under the electronic magnifier, which left small gaps between contacting surfaces. As thermal conduction coefficient of air was much lower than metal, thermal conduction across these gaps was significantly negatively impacted. In this case, thermal compound was essential to weaken this effect. Similar to $\mathrm{FR}_{2.3 .1}$, the demand range of $\mathrm{FR}_{2.3 .2}$ was inspired by heat releasing of CPU and GPU in the laptop, silicone thermal compound was applied to solve this case. Depending on the brands of thermal compound and laptop, thermal conduction coefficient generally varied between 4-7 W/mK. CPU and GPU temperature was significantly higher than balloon battery so $6 \mathrm{~W} / \mathrm{mK}$ thermal conduction coefficient should be sufficient, especially considering that thermal compound layer was thin. However, the higher the thermal conduction coefficient was, the better the performance would be. As for metal oxide thermal grease, it was a kind of compound which contained a high proportion of metal dust. Relatively, due to the high percentage of metal inside, its thermal conduction coefficient was higher than usual silicon thermal compound, which was around $26 \mathrm{~W} / \mathrm{mK}$ for the silver injected category. For thermal metal compound, which could be regarded as liquid metal, its thermal conduction coefficient could reach more than $100 \mathrm{~W} / \mathrm{mK}$. However, the thermal metal compound required strict electricity insulation treatment, and the price was relatively much higher either. The evaluation result was indicated in Figure 14. 


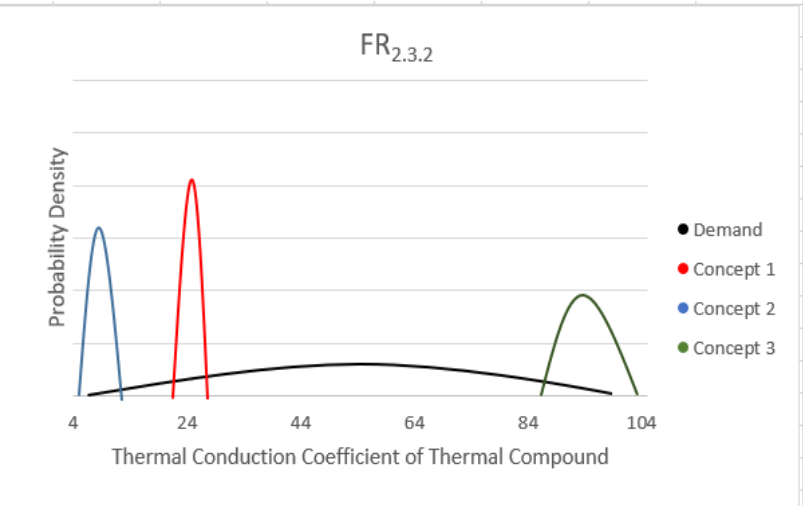

Fig. 14. $P D F$ for $\mathrm{FR}_{2.3 .2}$ Candidate DPs

To select the final concept, a Pugh's Matrix was made to compare each concept based on $\mathrm{CNs}$ and corresponding engineering characteristics(ECs). The ECs were listed as:

- $\mathrm{EC}_{1}$ : A heater to heat up the battery to a proper temperature.

- $\quad \mathrm{EC}_{2}$ : A heater to generate a high-temperature region.

- $\mathrm{EC}_{3}$ : A passive cooling system to cool down the region.

- $\mathrm{EC}_{4}$ : A battery fuel gauge and low-powerconsuming subsystems.

- $\quad \mathrm{EC}_{5}$ : An accelerometer.

- $\quad \mathrm{EC}_{6}$ : The code of BTC would be in Python.

- $\quad \mathrm{EC}_{7}$ : Interface bus and the electrical circuit.

- $\quad \mathrm{EC}_{8}: 10 \mathrm{~cm} \times 10 \mathrm{~cm}$ or smaller PCB.

- $\quad \mathrm{EC}_{9}$ : Dimensions of BTC and original PCB in total would be less than $12 \mathrm{~cm} \mathrm{x} 25 \mathrm{~cm} \times 10 \mathrm{~cm}$.

- $\quad \mathrm{EC}_{10}$ : Off-the-shelf components and materials.

- $\quad \mathrm{EC}_{11}$ : Low price components and materials.
- $\quad \mathrm{EC}_{12}$ : The whole construction should be finished by hand, bench work tools, milling machine, 3D printer and soldering tools.

The Pugh's matrix was shown in Table 2. The score of each criterion as classified into ' 0 ', ' 1 ' and 2. ' 0 ' represents 'not competent', ' 1 ' represents 'competent' and '2' represents 'highly competent'. The weights and scores were out of the discussion with several stakeholders. The result indicated that concept 1 was comprehensively the most appropriate selection. However, concept 2 was relatively at low cost and concept 3 relatively achieved main FRs better. These two concepts might still be useful for future development.

Table.2. Pugh's Matrix of Three Candidate Concepts

\begin{tabular}{|c|c|c|c|c|c|}
\hline CNs & ECs & Weight & $\begin{array}{c}\text { Concept } \\
1 \\
\end{array}$ & $\begin{array}{c}\text { Concept } \\
2 \\
\end{array}$ & $\begin{array}{c}\text { Concept } \\
\mathbf{3} \\
\end{array}$ \\
\hline $\mathrm{CN}_{1}$ & $\mathrm{EC}_{1}$ & 5 & 2 & 1 & 2 \\
\hline $\mathrm{CN}_{2}$ & $\mathrm{EC}_{2}$ & 4 & 1 & 1 & 2 \\
\hline $\mathrm{CN}_{3}$ & $\mathrm{EC}_{3}$ & 5 & 2 & 1 & 1 \\
\hline $\mathrm{CN}_{4}$ & $\mathrm{EC}_{4}$ & 3 & 2 & 1 & 0 \\
\hline $\mathrm{CN}_{5}$ & $\mathrm{EC}_{5}$ & 3 & 1 & 1 & 2 \\
\hline $\mathrm{CN}_{6}$ & $\mathrm{EC}_{6}$ & 4 & 1 & 1 & 1 \\
\hline $\mathrm{CN}_{7}$ & $\mathrm{EC}_{7}$ & 2 & 1 & 1 & 1 \\
\hline $\mathrm{CN}_{8}$ & $\mathrm{EC}_{8}$ & 1 & 1 & 1 & 1 \\
\hline $\mathrm{CN}_{9}$ & $\mathrm{EC}_{9}$ & 1 & 1 & 1 & 1 \\
\hline $\mathrm{CN}_{10}$ & $\mathrm{EC}_{10}$ & 2 & 2 & 2 & 1 \\
\hline $\mathrm{CN}_{11}$ & $\mathrm{EC}_{11}$ & 3 & 1 & 2 & 0 \\
\hline $\mathrm{CN}_{12}$ & $\mathrm{EC}_{12}$ & 1 & 1 & 1 & 0 \\
\hline \multicolumn{3}{|c|}{ Total } & 49 & 39 & 39 \\
\hline
\end{tabular}

\subsection{FR-DP Hierarchy and CAD Model}

A final FR-DP hierarchy was made for concept 1 as shown in Figure 15. Bottom-level DPs were made corresponding to Morphological Chart, and assigned

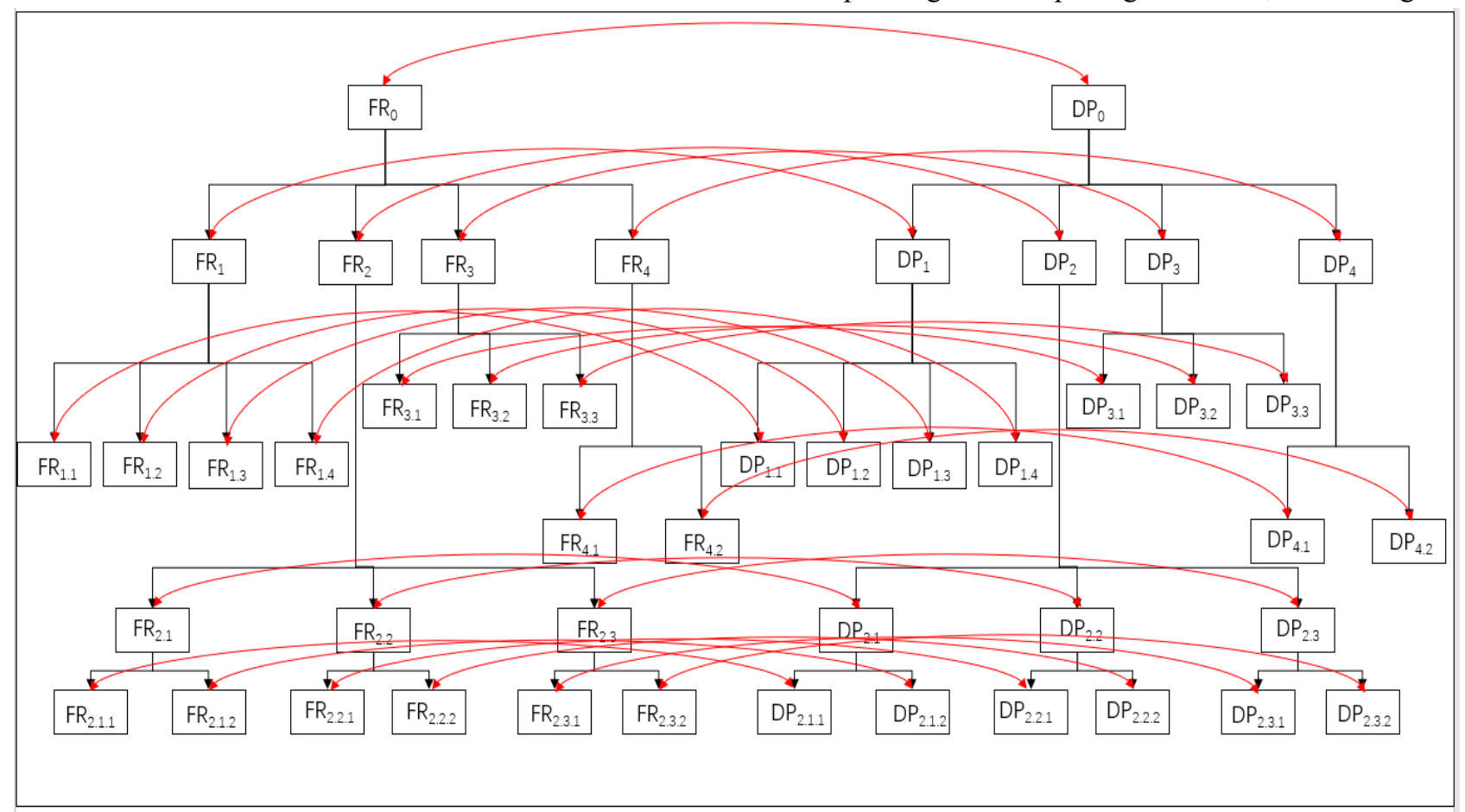

Fig. 15. FR-DP Hierarchy of Concept 1 
numbers were referring to bottom-level FRs. Some additional high-level DPs were added including:

- $\mathrm{DP}_{0}$ : Battery thermal controller

- $\mathrm{DP}_{1}$ : Sensors with the $\mathrm{I} 2 \mathrm{C}$ interface bus

- $\mathrm{DP}_{2}$ : Thermal control system

- $\mathrm{DP}_{3}: \mathrm{I} / \mathrm{O}$ expanders with the I2C interface bus

- $\quad \mathrm{DP}_{4}$ : Standard PCB base with expansion pins

- $\quad \mathrm{DP}_{2.1}$ : Heat generator and preservation system

- $\mathrm{DP}_{2.2}$ : Overheating simulation region with the cooling system

- $\quad \mathrm{DP}_{2.3}$ : Thermal conduction materials

A CAD model draft was made of concept 1 as shown in Figure 16 and 17. Figure 16 was the isometric view of BTC, while Figure 17 displayed the schematic of original balloon PCB. This CAD model was just an illustrative example, component types, layout, specific dimensions and appearance were not determined yet.

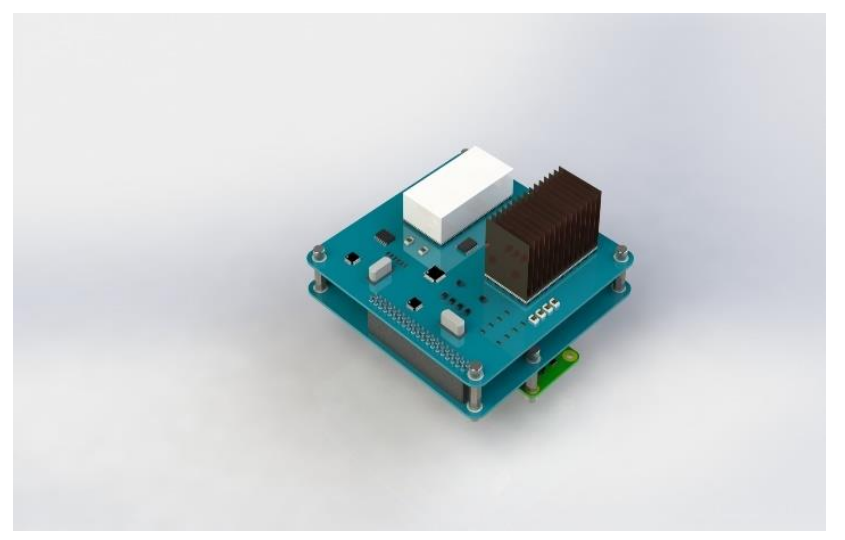

Fig. 16. Isometric View of BTC

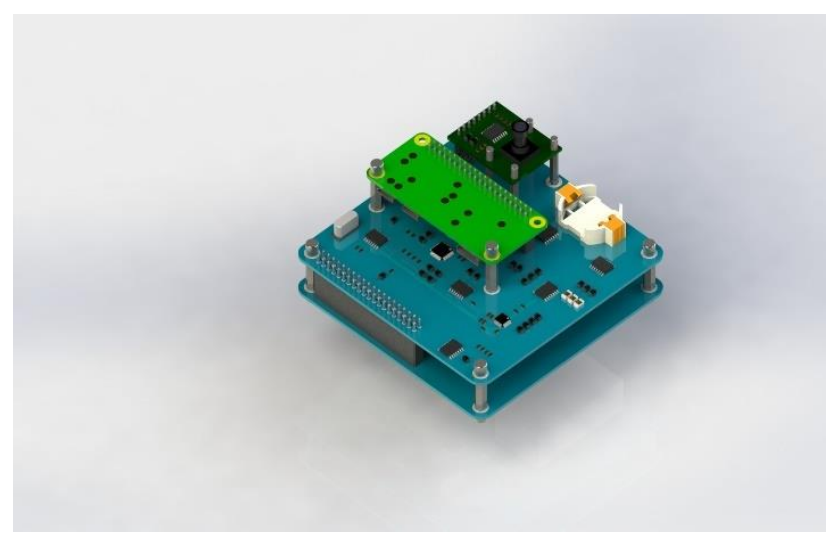

Fig. 17. Isometric View of Original PCB

\section{Discussion and Reflection}

\subsection{Benefits}

Design is primarily an information processing activity. A significant amount of scattered information is involved in customer domain, functional domain and concept domain. With the axiomatic design, scattered information becomes well-organised.

This significantly benefits two aspects. One is design mistake correction. Through the axiomatic design process, logical bonds are formulated among the three domains, customer domain determines FRs and constraints, FRs will determine candidate DPs, and DPs compose into concepts, which will be evaluated according to CNs. Except for this sequence, feedback process also exists within this design sequence. These characteristics make mistakes more accessible to be noticed, while correction can be made to target procedure accurately by reviewing the design sequence. For instance, in the information axiom design procedure, when candidate DPs are compared via probability density functions, if a candidate DP is entirely out of demand scope, and there is no sufficient reason to support its validation as an exception, this DP then can be regarded as inappropriately generated DP. A new competent DP would replace it. Like the dissipation coating of $\mathrm{FR}_{2.2 .2}$, the performance value is entirely out of demand range, which demonstrated that it should be replaced. However, dissipation coating is cheap and manufacture-friendly, if the practical test proves that demand range can be more liberal or budget need reducing, it will be competitive. Consequentially, it becomes an exception. Another example is the FR-DP matrix. From the matrix, it can be noticed if the concept is uncoupled design. If not, independence of FRs or DPs should be revised.

The other aspect is competent and convenient-use concepts generation. When design objectives are assigned, students might incline to two trends. One is applying redundant DPs to secure the achievement of FRs. The other is using insufficient DPs to minimise some constraints like size and cost. Essentially, both trends are due to lack of experience, which makes students unconfident in achieving FRs or securing constraints with a certain amount of DPs. Following these trends, redundant DPs leads to over-constraint characteristics, while insufficient DPs causes incompetence or inconvenient use. With the axiomatic design, FRs are kept independent, and DPs will be generated correspondingly under control of constraints and $\mathrm{CNs}$, which make the final concept both competent and irredundant. For example, for $\mathrm{FR}_{2.1 .1}$ and $\mathrm{FR}_{2.2 .1}$, without the organisation of axiomatic design, students might use a large heater to heat up both regions at the same time, which will formulate a coupled design with FRs that are relevant to automatic control. Consequentially, BTC will not achieve independent control in heaters and heat region.

\subsection{Challenges}

Through this high-altitude balloon design process, two challenging parts were noticed. One is determining the performance value range for demand and DPs in information axiom design part. To make the demand value and DPs performance value accurate and valid, a rigorous process should generally include four steps. First one is an initial estimation based on previous experience. The second is searching for academic resources about similar design. Then it comes to data analysis from experiment under strict environmental control. Finally, practical application will give feedback to design quality. However, students usually are lack of industrial experience and professional experimental apparatus. Besides, data from similar design test is not readily 
accessible either. Due to these constraints, students might just evaluate based on simple prototype test like $\mathrm{FR}_{2.1 .1}$ or reference from similar DPs like $\mathrm{FR}_{2.3 .2}$. The only accurate data feedback might be the final application in this case.

The other challenging part is improving physical integrity of composed design concept while maintaining functionally independent. In customer domain, CNs relevant to size, price and convenience appear at a critically high frequency. Physical integrity extent of design significantly affects these three CNs. However, DPs are generated from FRs while FRs are secured to be independent of each other through independence axiom design. As a result, DPs are relatively independent of each other as well. In concept visualisation part, it could be seen that 15 DPs mostly correspond to 15 components. Integrating physical DPs on fewer elements requires qualified design principle education, design experience and students' creation, of which a large proportion of undergraduate students might not be capable. More importantly, if the inappropriate attempt of integrating is made, the design might not be uncoupled anymore.

\subsection{Potential Mistakes}

Through interviews with some students and the reflection of fore-procedures, two common mistakes were observed at a high probability. One is generating inconsistent demand value for bottom-level FRs. The functional hierarchy had been modified several times to formulate the current version. When the functional hierarchy was firstly done, some inconsistent demand value existed for some bottom-level FRs. For instance, initially, $\mathrm{FR}_{3.1}$ was 'Terminate heating system when the temperature is higher than $15^{\circ} \mathrm{C}$.' This FR should be achieved by a logical switch. However, the demand value was 'when the temperature is higher $15^{\circ} \mathrm{C}$ ', which was a requirement for a temperature sensor. Another example is that in a student vehicle design project, a similar case was observed as 'Decelerate to $10 \mathrm{~cm} / \mathrm{s}$ when the load is heavier than $300 \mathrm{~g}$ ', deceleration should be achieved by power system and brake system, while 'when the load is heavier than $300 \mathrm{~g}$ ' is achieved by a pressure sensor. Primarily, this problem happens at higher probability when dealing with conditional FR, which means the FR will perform under a specific condition, just like the $15^{\circ} \mathrm{C}$ temperature and $300 \mathrm{~g}$ load mentioned in the two examples.

The other potential mistake is generating invalid candidate DPs and concepts in concept domain. After obtaining customers' demands, students might already have a general design concept idea. This idea would be potentially inclined in rest design procedures. If the DPs and concepts generation is an isolation task, to filter out this preferred concept as the final result, students might deliberately generate invalid DPs which seem reasonable but incompetent to make a comparison. For instance, if copper is the preferred candidate DP to serve $\mathrm{FR}_{2.3 .1}$, to filter it out, carbon steel and artificial diamond could be used to replace aluminium and silver-plated copper. Carbon steel is utilised for many cookers, and artificial diamond has the thermal conduction coefficient at around $1000 \mathrm{~W} / \mathrm{mK}$. These two DPs seem rational, but thermal conduction coefficient of carbon steel is just around $100 \mathrm{~W} / \mathrm{mK}$, and artificial diamond is too expensive, which make them both not competent to meet customers' demands. Consequentially, information axiom design is meaningless in this case. The possible motivation behind this is saving time for students while the design logic still makes sense. This problem might occur when the axiomatic design assignment time is intense, which should be paid attention to student education.

\section{Conclusion and Future Work}

In conclusion, the axiomatic design effectively assists this student lead project. However, due to invoice students' inherent constraints, some procedures can be difficult to properly apply. For benefits, the axiomatic design made the information processing well-organised, which significantly assist mistakes correction, and generating competent and convenient-use concepts. As for challenges, students might find it hard to determine demand and performance value for DPs when evaluating the competence of DPs with probability density function graph due to lack of experience, resources and experiment apparatus. Increasing physical integration extent for composed concepts was the other challenge. For potential mistakes, generating unmatched performance demand value for bottom-level FRs could be a possible mistake, while generating incompetent DPs should be focused as well.

Regarding future work, firstly, based on mentioned challenges and potential mistakes in this design application, corresponding education strategies will be researched. These strategies will focus on guiding invoice students to make rational and objective decisions with available resources to offset their inherent constraints. Candidate strategies include making simple prototypes, academic resources cloud searching and peer reviews. Secondly, the BTC is currently under manufacturing, and it will be tested in spring. Based on practical test results, the second-round reflection will be made. The validation of this axiomatic design will be assessed according to practical test result. When the test data is retrieved, an analysis will be made to classify successful design parts and incompetent design parts. Corresponding to the analysis result, benefits, mistakes of axiomatic design application will be discussed at a further level. Meanwhile, for those incompetent DPs, the failure of theory application will be reflected, education strategies that assist students to utilise the axiomatic design more effectively will be researched in correspondence.

\section{References}

1. J. Wilson, F. Badavi, M. Kim, M. Clowdsley, J. Heinbockel, F. Cucinotta, G. Badhwar, W. Atwell, S. Huston, Natural and Induced Environment in Low Earth Orbit, NASA, Virginia, (2002)

2. E. Weast, Handbook of Chemistry and Physics, The Chemical Rubber Co, Ohio, (1964) 
3. B. Kumar, L. Scanlon, MATER. RES. SOC. SYMP. P 124, 239 (1999)

4. K. Hirano, M. Asami, REACT. FUNCT. POLYM 73, $256(2012)$

5. A. Papadopoulos, ENERG BUILDINGS 37, 77 (2005)

6. D. Chung, APPL THERM ENG 21, 1593 (2001)

7. S. Zhang, K. Xu, T.Jow, J POWER SOURCES 115, 137 (2003)

8. T. Bergman, A. Lavine, F. Incropera, D. DeWitt, Introduction to Heat Transfer (John Wiley \& Sons, Inc, US, 2011)

9. J. Shim, R. Kostecki, T. Richardson, X. Song, K. Striebel, J POWER SOURCES 112, 222 (2002)

10. A. Korjenic, V. Petranek, J. Zach, J. Hroudova, ENERG BUILDINGS 43, 2518 (2011)

11. X. Cao, R. Vassen, D. Stover, J EUR CERAM SOC 24, 1 (2004)

12. C. Andrade, E. Zaparoli, J BRAZ SOC MECH SCI 22, (2000)

13. G. Kalaprasad, P. Pradeep, G. Mathew, C. Pavithran, S. Thomas, COMPOS SCI TECHNOL 60, 2967 (2000)

14. A. Demharter, CRYOGENICS 38, 113 (1998)

15. D. Chung, APPL THERM ENG 21, 1593 (2001) 